\title{
Uso da Ocitocina na Estimativa de Produção e Composição do Leite de Ovelhas Hampshire Down
}

\author{
Edson Luis de Azambuja Ribeiro', Ivone Yurika Mizubuti ${ }^{1}$, Marco Antonio da Rocha ${ }^{2}$, Leandro \\ das Dores Ferreira da Silva ${ }^{2}$, Helena Bergamo ${ }^{3}$, Rinaldo Masato Mori ${ }^{4}$, Marcos Rodrigues \\ Podleskis $^{4}$, Danilo Laurenti Ferreira ${ }^{5}$
}

\begin{abstract}
RESUMO - Com este trabalho, objetivou-se estimar a produção de leite por meio de ordenha manual usando diferentes doses de ocitocina via intramuscular $(1 ; 2 ; 3 ; 4$ e 5 UI). Foram utilizadas 10 ovelhas Hampshire Down adultas, distribuídas em um delineamento em quadrado latino repetido 5 x 5 (cinco ovelhas e cinco dias de estimativa de produção de leite). A ordenha foi realizada após uma separação de 4 horas dos cordeiros, sendo a produção corrigida para 24 horas. No último dia de estimação, as ovelhas foram ordenhadas em quatro horários (12h30, 18h30, 24h30 e 06h30), para determinar qual período de ordenha apresentava a maior correlação com a produção total diária. Não foram observadas diferenças significativas entre as doses de ocitocina, de $1 ; 2 ; 3 ; 4$ e 5 UI, na produção de leite, sendo, respectivamente, de 1020,80; 936,20;1028,40;1235,40 e 1159,80 g. A composição do leite também não foi afetada pelas doses de ocitocina e as médias para porcentagens de sólidos totais, proteína bruta, lactose e gordura foram, respectivamente, de 17,3;4,3;3,8 e 7,4\%. As correlações entre as estimativas obtidas nos quatro períodos de ordenha e a produção total diária variaram de 0,71 a 0,97 . Portanto, para a estimativa de produção de leite diária pode ser recomendada a menor dose de ocitocina (1 UI) e apenas uma ordenha diária, com separação do cordeiro por 4 horas.
\end{abstract}

Palavras-chave: gordura, habilidade materna, lactação, ordenha, ovinos, proteína bruta

\section{Use of Oxytocin to Estimate Milk Production and Composition in Hampshire Down Ewes}

ABSTRACT - The objective of this work was to estimate milk production through hand milking, using different doses $(1 ; 2 ; 3 ; 4$; and 5 IU) of oxytocin intramuscularly. Ten adult Hampshire Down ewes were assigned to a $5 \mathrm{x} 5$ repeated Latin square design, with five ewes and five days. Milking was performed after a 4-hour lamb separation period, and then corrected to 24 hours. On the last day of estimation, the ewes were milked at four different times, 12:30 p.m.; 06:30 p.m.; 12:30 a.m. and 06:30 a.m.. This procedure was done to estimate which milking period showed greater correlation with the total daily milk production. No significant differences were observed among oxytocin doses in the milk production. Milk production averages for 1; 2; 3; 4 e 5 IU doses were, respectively, 1020.80; 936.20; $1028.40 ; 1235.40$ and $1159.80 \mathrm{~g}$. Milk composition was not affected by oxytocin doses, either. Averages for total solids, crude protein, lactose and fat were, respectively, $17.3 ; 4.3 ; 3.8$ and $7.4 \%$. Correlation among the milk production estimates obtained in the four milking periods and the total daily milk production ranged from 0.71 to 0.97 . Therefore, for daily milk production estimate, it can be recommended the smallest dose (1 IU) of oxytocin and only one daily milking, with lamb separation of 4 hours.

Key Words: crude protein, fat, lactation, maternal ability, milking, sheep

\section{Introdução}

A indústria ovina tem sido pressionada a buscar eficiência de produção de cordeiros e viabilidade de produtos dos mesmos com o aumento do peso de abate e da qualidade de carcaça. A eficiência e o tempo requerido para que o cordeiro atinja o peso de abate exigido são críticos na otimização da lucratividade (Ramsey et al., 1998), sendo que o crescimento inicial é afetado, principalmente, pelo leite materno (Minola \& Goyenechea, 1975; Snowder \& Glimp, 1991; Ramsey et al., 1994).

O leite produzido pelas ovelhas, sobretudo nas primeiras semanas de vida, é a principal fonte de alimentação para o cordeiro e fornece os nutrientes necessários em um período em que o potencial de crescimento é mais elevado. A deficiência na produção de leite poderá afetar seriamente a saúde e o

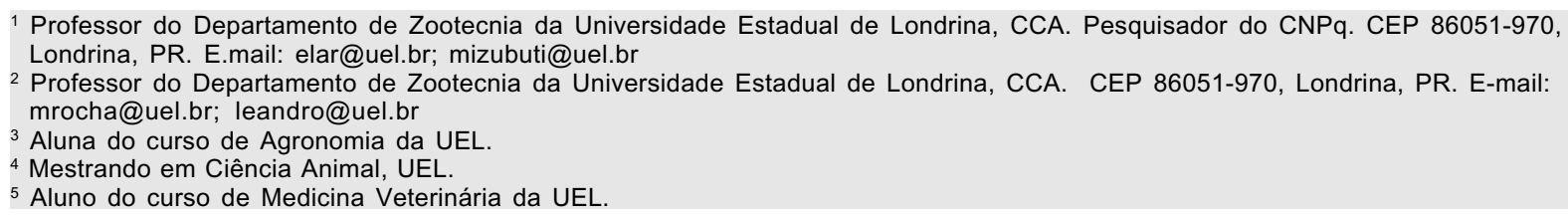


desenvolvimento e, conseqüentemente, a produção futura do animal (Minola \& Goyenechea, 1975). Portanto, é importante quantificar a produção de leite das ovelhas visando determinar a sua influência sobre o desempenho dos cordeiros. De maneira similar, a composição do leite é muito importante. Geenty (1979) observou que a proteína e os sólidos não gordurosos do leite foram significativamente correlacionados com o peso dos cordeiros.

A ejeção do leite e sua completa remoção do úbere são o resultado de um mecanismo neuroendócrino, que induz a contração alveolar e a expulsão do leite secretado (Marnet \& McKusick, 2001). A ocitocina - hormônio responsável pela ejeção do leite - é sintetizada no hipotálamo, armazenada na neuro-hipófise e produzida também no corpo lúteo. Sua ação ocorre sobre as fibras musculares lisas, estimulando sua contração (Hafez, 1995). Nos mamíferos, a secreção de ocitocina segue a estimulação da glândula mamária durante a amamentação ou ordenha.

Minola \& Goyenechea (1975) comentaram que quantificar a produção leiteira de ovelhas a campo é uma tarefa difícil, pois a separação dos cordeiros em diferentes intervalos durante o dia pode alterar o hábito de pastoreio e o mecanismo de produção láctea. Doney et al. (1979) afirmam que para se estimar a produção de leite de ovelhas pode-se utilizar a dupla pesagem do cordeiro, antes e após a mamada, ou a ordenha manual ou mecânica da ovelha após administração de ocitocina. Wohlt et al. (1984) compararam os métodos da dupla pesagem do cordeiro e da ordenha manual na estimativa de produção de leite e observaram que em ovelhas com cordeiros únicos, a dupla pesagem subestimou a produção nas primeiras seis semanas, pois os cordeiros deixavam leite residual no úbere. Este problema não ocorria com as ovelhas com gêmeos. Lemos Neto \& Cunha (1994) também compararam os métodos da dupla pesagem dos cordeiros e da ordenha manual e não observaram diferenças entre os dois métodos na estimativa de produção de leite, a não ser na oitava semana de lactação. Nos seus experimentos, Wohlt et al. (1984) e Lemos Neto \& Cunha (1994) utilizaram intervalos de 4 horas entre as ordenhas, enquanto Minola \& Goyenechea (1975) recomendaram intervalos de 6 horas entre as medições de produção de leite. Por outro lado, Ramsey et al. (1994) optaram por intervalos de separação dos cordeiros de 2 a 3 horas, pois correspondem ao intervalo normal de mamadas dos cordeiros. Em relação ao desempenho do cordeiro, Godfrey et al. (1997) observaram que, na estimativa semanal de produção de leite, com separação dos cordeiros por quatro horas, os animais tiveram ganhos de peso até o desmame similar a cordeiros filhos de ovelhas que não estavam sendo avaliadas para produção de leite.

Bencini et al. (1992) avaliaram a técnica de medir a produção de leite pela ordenha precedida por injeção de ocitocina, em doses de 0,0; 0,5; 1,0 e 5,0 UI via intravenosa (jugular), e observaram diferença na estimativa de produção de leite entre a dose 0,0 , ou seja, sem ocitocina, e as demais doses. Também observaram diferenças entre as doses 0,5 e 5,0, mas não entre as doses 1,0 e 5,0 UI. Porém, diferentes doses de ocitocina e vias de aplicação têm sido relatadas na literatura. Para via intravenosa, os valores variam de 1 a 20 UI (Corbett, 1968; Doney et al., 1979; Geenty, 1979; Godfrey et al., 1997; Ramsey et al., 1998). Em aplicação intramuscular, Wohlt et al. (1984) utilizaram a dose de 6 UI, enquanto Lemos Neto \& Cunha (1994), 5 UI. Segundo Marnet \& McKusick (2001) pequenos aumentos acima do nível basal de ocitocina são suficientes para promover a ejeção do leite em ruminantes.

Neste trabalho, objetivou-se avaliar diferentes doses de ocitocina, aplicadas via intramuscular, na estimativa de produção diária de leite e na composição do leite de ovelhas Hampshire Down, além de determinar as correlações entre as produções de leite obtidas em períodos de 4 horas, em diferentes horários do dia, com a produção diária total de leite.

\section{Material e Métodos}

O experimento foi conduzido no setor de ovinocultura da Fazenda Escola da Universidade Estadual de Londrina, no município de Londrina, Paraná. Foram utilizados dois grupos com cinco ovelhas Hampshire Down adultas, com peso médio de $51 \mathrm{~kg}$, amamentando cordeiros únicos. O primeiro grupo de ovelhas estava, aproximadamente, com 30 dias de lactação e o segundo, com 70 dias. Cada grupo foi distribuído em delineamento em quadrado latino 5 x 5 (cinco ovelhas e cinco dias de avaliação, com cinco tratamentos). Os animais foram mantidos em pastagem de capim-Coastcross (Cynodon dactylon (L.) Pers).

A produção de leite das ovelhas foi avaliada após 4 horas de separação do cordeiro, por ordenha manual, 
e a quantidade coletada foi corrigida para 24 horas, para avaliar a estimativa da produção diária. Nos dias de avaliação, os cordeiros eram separados de suas mães às $6 \mathrm{~h} 30$. Visando o completo esvaziamento do úbere das ovelhas, às $8 \mathrm{~h}$, estas eram novamente unidas a seus cordeiros por 30 minutos, permitindo que mamassem. Às $8 \mathrm{~h} 30$, as ovelhas eram conduzidas aos piquetes de pastagem e seus cordeiros permaneciam estabulados, separados de suas mães por 4 horas. Às $12 \mathrm{~h} 30$, as ovelhas eram reconduzidas ao estábulo, e recebiam injeção de ocitocina, via intramuscular, e eram ordenhadas manualmente. No último dia de avaliação, foram também ordenhadas às $18 \mathrm{~h} 30,24 \mathrm{~h} 30$ e $6 \mathrm{~h} 30$. Os cordeiros eram colocados com as ovelhas após a ordenha e posteriormente separados para que transcorresse o período de separação de 4 horas. Amostras do leite das ordenhas das $12 \mathrm{~h} 30$ foram congeladas e armazenadas para posterior análise de sua composição. Foram determinados os teores de gordura, de lactose, de proteína e de sólidos totais (Instituto Adolfo Lutz, 1985).

No primeiro dia de avaliação, cada ovelha recebeu uma das seguintes doses de ocitocina: 1, 2, 3, 4 ou 5 UI. As avaliações seguintes foram feitas a cada 48 horas, totalizando cinco avaliações, em que receberam doses de ocitocina diferentes daquelas recebidas nas avaliações anteriores. Os dados foram submetidos à análise de variância, considerando-se o delineamento experimental em quadrado latino repetido 5x5 (Lentner \& Bishop, 1986), segundo o modelo matemático abaixo:
$\mathrm{Y}_{\mathrm{gijk}}=\mu+\mathrm{Q}_{\mathrm{g}}+\mathrm{D}(\mathrm{Q})_{\mathrm{gi}}+\mathrm{O}(\mathrm{Q})_{\mathrm{gj}}+\mathrm{T}_{\mathrm{k}}+(\mathrm{QT})_{\mathrm{gk}}+\mathrm{e}_{\mathrm{gijk}}$

em que: $Y_{\text {gijk }}=$ é a observação referente ao g-ésimo quadrado, ao i-ésimo dia de avaliação dentro do gésimo quadrado, à j-ésima ovelha dentro do g-ésimo quadrado, ao k-ésimo tratamento e à interação entre o g-ésimo quadrado e o k-ésimo tratamento; $\mu=$ efeito médio; $\mathrm{Q}_{\mathrm{g}}=$ efeito do g-ésimo quadrado; $\mathrm{D}(\mathrm{Q})_{\mathrm{gi}}=$ efeito do i-ésimo dia de avaliação dentro do g-ésimo quadrado; $\mathrm{O}(\mathrm{Q})_{\mathrm{gj}}=$ efeito da j-ésima ovelha dentro do g-ésimo quadrado; $\mathrm{T}_{\mathrm{k}}=$ efeito do k-ésimo tratamento; $(\mathrm{QT})_{\mathrm{gk}}=$ efeito da interação entre o g-ésimo quadrado e o k-ésimo tratamento; e $\mathrm{e}_{\mathrm{gijk}}=$ erro aleatório associado a cada observação.

Realizou-se, também, a correlação das estimativas de produção diária de leite obtidas em cada um dos quatro períodos do último dia de avaliação, com a produção total diária obtida pelo somatório dos quatro períodos. Para as análises estatísticas, utilizou-se o pacote estatístico SAS (SAS, 1994).

\section{Resultados e Discussão}

Na Tabela 1, são apresentadas as médias de produção do leite das ovelhas, de acordo com os tratamentos. Observa-se que não houve diferença estatística $(\mathrm{P}>0,05)$ entre as diferentes doses de ocitocina na estimativa da produção de leite. $\mathrm{Na}$ literatura, alguns trabalhos têm sugerido diferentes doses de ocitocina. Contudo, Bencini et al. (1992) não observaram diferenças entre as doses 1 e 5 UI aplicadas

Tabela 1 - Médias de produção (g) diária de leite em ovelhas Hampshire Down, de acordo com a dose de ocitocina usada Table 1 - Means for daily milk production $(g)$ in Hampshire Down ewes, according to the oxytocin dose

\begin{tabular}{lccc}
\hline $\begin{array}{l}\text { Dose de ocitocina, UI } \\
\text { Oxytocin dose, } I U\end{array}$ & $\begin{array}{c}\text { 30 dias de lactação } \\
\text { 30 days oflactation }\end{array}$ & $\begin{array}{c}70 \text { dias de lactação } \\
70 \text { days of lactation }\end{array}$ & $\begin{array}{c}\text { Produção média } \\
\text { Average production }\end{array}$ \\
\hline 1 & 1244,40 & 797,20 & $1020,80^{\mathrm{a}}$ \\
2 & 936,80 & 935,60 & $936,20^{\mathrm{a}}$ \\
3 & 1111,60 & 945,20 & $1028,40^{\mathrm{a}}$ \\
4 & 1332,40 & 1138,40 & $1235,40^{\mathrm{a}}$ \\
5 & 1368,80 & 950,80 & $1159,80^{\mathrm{a}}$ \\
Média geral & $1198,80^{\mathrm{a}}$ & $953,44^{\mathrm{b}}$ & 1076,12 \\
Overall mean & & & \\
\hline
\end{tabular}

Médias na coluna seguidas por letras iguais não diferem estatisticamente $(P>0,05)$.

Médias na linha seguidas por letras diferentes, diferem estatisticamente $(P<0,05)$.

Means, within a column, followed by the same letter do not differ statistically $(P>05)$.

Means, within a row, followed by different letters differ statistically $(P<.05)$. 
via intravenosa e relataram que o método da ocitocina é confiável para mensurar a produção de leite em ovelhas, ao paso que Corbett (1968) comentou que, em alguns casos, a dose de 3UI via intravenosa não era suficiente para a extração de leite, havendo a necessidade de segunda dose, enquanto, em muitos casos, apenas 1 UI seria suficiente para a completa ejeção do leite.

A produção de leite foi maior nas ovelhas que estavam no 30 으 dia de lactação que nas que estavam no $70^{\circ}$ dia (Tabela 1 ), corroborando os resultados de Minola \& Goyenechea (1975), cujo pico de produção ocorreu, aproximadamente, na quarta semana de lactação, com posterior decréscimo de produção. Estes autores relataram produções de 0,77 a 2,20 kg/dia no pico de produção para ovelhas de raças não-leiteiras, e citaram que entre os fatores que afetam a produção leiteira, destacam-se a nutrição, o peso vivo, o número de cordeiros criados e a idade da ovelha. Godfrey et al. (1997) observaram produções decrescentes dos sete aos 63 dias de lactação, em ovelhas Barriga Negra de Barbados e St. Croix White. Outros autores reportaram resultados similares (Geenty, 1979; Wohlt et al., 1984; Ramsey et al., 1994).

Não houve diferenças na composição do leite segundo as diferentes doses utilizadas (Tabela 2). Bencini et al. (1992) não observaram diferenças no teor de gordura do leite entre diferentes doses de ocitocina utilizadas. Zamiri et al. (2001), por sua vez, observaram maiores teores de gordura e sólidos totais no leite de ovelhas que receberam ocitocina diariamente durante a lactação, comparadas com aquelas que não receberam. Os teores de proteína e de lactose, entretanto, não foram afetados pelo uso de ocitocina.

De maneira geral, as médias de sólidos totais e de gordura estiveram de acordo às relatadas por Boylan (1989), porém as médias de proteína e lactose foram menores que as observadas por aquele autor. Os teores de gordura e de lactose foram semelhantes aos observados por Snowder \& Glimp (1991), porém o teor de proteína foi menor que o descrito pelos autores. Ramsey et al. (1998) verificaram médias de sólidos totais, de gordura e de proteína superiores às observadas no presente trabalho, porém as médias do teor de lactose foram bastante próximas. Esses autores registraram grande variação nos teores dos componentes do leite ao longo da lactação e também entre raças. Minola \& Goyenechea (1975) citaram as porcentagens de 19,$9 ; 5,8 ; 4,8$ e 8,2 , respectivamente, para sólidos totais, proteína bruta, lactose e gordura, como valores médios para o leite de ovelhas.

Em relação às mudanças durante a lactação, os resultados se assemelham aos os de Wohlt et al. (1984), que também observaram menores teores de proteína e de gordura no leite na quarta semana de

Tabela 2 - Médias de composição (\%) do leite de ovelhas Hampshire Down, de acordo com a dose de ocitocina aplicada e o dia da lactação

Table 2 - Means for milk composition (\%) of Hampshire Down ewes, according to oxytocin dose and lactation day

\begin{tabular}{lcccc}
\hline Item & Sólidos totais & Proteína bruta & Lactose & Gordura \\
& Total solids & Crude protein & Lactose & Fat \\
\hline
\end{tabular}

Dose ocitocina, UI

Oxytocin dose, $I U$

1

$2 \quad 16,8$

$3-16,7$

$4 \quad 17,8$

18,3

18,3

$4,6 \quad 4,1$

$4,1 \quad 3,9$

$4,2 \quad 3,7$

$4,1 \quad 3,7$

Dia da lactação

3,8

Lactation day

30

$19,9^{\mathrm{b}}$

Média geral

17,3

\section{$4,0^{\mathrm{a}}$ \\ $4,6^{\mathrm{b}}$}

4,3

$4,0^{\mathrm{a}}$
$3,7^{\mathrm{b}}$
3,8

Overall mean

$(\mathrm{P}>0,05)(P>05)$. 
lactação, em relação ao leite da oitava semana. Quanto à lactose, esses autores, também observaram valor numérico menor na oitava semana, porém não diferente estatisticamente. Ramsey et al. (1998) notaram que o teor de gordura no leite diminuiu com o avançar da lactação, ao passo que, para os demais componentes, o comportamento foi similar aos observados no presente estudo. Por outro lado, Geenty (1979) não observou mudanças nos principais componentes do leite entre a sexta e a décimasegunda semana de lactação. Lemos Neto \& Cunha (1994) verificaram redução no teor de proteína da primeira à quinta semana de lactação, com aumento posterior até a oitava semana. Para o teor de gordura, os autores não observaram mudanças significativas. A nutrição pode ser um importante fator a afetar a composição do leite, uma vez que baixo plano nutritivo pode acarretar diminuição dos teores de gordura, de proteína e de sólidos totais e elevar o teor de lactose (Minola \& Goyenechea, 1975).
As correlações entre as estimativas de produção de leite em diferentes períodos do dia com a produção diária total são apresentadas na Tabela 3 . As estimativas de produção de leite nos quatro períodos ao longo do dia tiveram correlações altas e significativas com a produção diária total (24 horas). A menor correlação foi observada para a estimativa realizada no período da tarde (P2 ou 18h30) e a maior foi aquela estimada pelo somatório das ordenhas realizadas ao meio-dia e as da tarde (P1-2), que foram, respectivamente, de 0,71 $(\mathrm{P}<0,05)$ e $0,98(\mathrm{P}<0,01)$. As estimativas realizadas ao meio-dia (P1), à meia-noite (P3) e pela manhã (P4) apresentaram correlações com a produção total, altas e muito próximas da estimativa feita pelo somatório das ordenhas realizadas pela manhã e pela tarde (P1-2). Estes resultados contrariam as observações de Corbett (1968), que não encontrou diferença nas estimativas obtidas em diferentes horários do dia.

Tabela 3 - Correlações entre as produções diárias de leite obtidas em diferentes períodos do dia e a produção diária total de leite

Table 3 - Correlations between milk daily productions obtained at different periods of the day and the total daily milk production

\begin{tabular}{lcccccc}
\hline Períodos $^{\mathrm{a}}$ & \multicolumn{5}{c}{ Períodos $^{1}$} \\
Periods $^{a}$ & \multicolumn{7}{c}{ Periods $^{1}$} \\
\cline { 2 - 7 } & P1 & P2 & P3 & P4 & P1-2 & P-Total \\
\hline P1 & - & 0,58 & $0,93^{* *}$ & $0,95^{* *}$ & $0,95^{* *}$ & $0,97^{* *}$ \\
P2 & & - & $0,65^{*}$ & 0,49 & $0,81^{* *}$ & $0,71^{*}$ \\
P3 & & & - & $0,93^{* *}$ & $0,92^{* *}$ & $0,97^{* *}$ \\
P4 & & & & - & $0,87^{* *}$ & $0,95^{* *}$ \\
P1-2 & & & & & - & $0,98^{* *}$ \\
\hline
\end{tabular}

$1 \mathrm{P} 1=$ Ordenha realizada às $12 \mathrm{~h} 30 ; \mathrm{P} 2=$ Ordenha realizada às $18 \mathrm{~h} 30 ; \mathrm{P} 3=$ Ordenha realizada às $24 \mathrm{~h} 30 ; \mathrm{P} 4=$ Ordenha realizada as $06: 30 \mathrm{hs} ; \mathrm{P} 1-2=$ Somatória das ordenhas das $12 \mathrm{~h} 30$ às $18 \mathrm{~h} 30 ; \mathrm{P}$-Total = Somatório dos quatro períodos. ${ }^{1} P 1=$ Milking at 12:30 pm; $P 2=$ Milking at 06:30 pm; P3 = Milking at 12:30 am; P4 = Milking at 06:30 am; $P 1-2=$ Sum of milking at $12: 30$ $\mathrm{pm}$ and 06:30 pm; P-Total $=$ Sum of the four periods.

${ }^{*}(\mathrm{P}<0,05) ;{ }^{* *}(\mathrm{P}<0,01)$. 


\section{Conclusões}

Não foram detectadas diferenças significativas entre as diferentes doses de ocitocina utilizadas, nas estimativas de produção e composição do leite, sendo então recomendada a utilização de $1 \mathrm{UI}$.

Os resultados indicaram não ser necessário ordenhar a ovelha por 24 horas para se estimar a sua produção de leite.

A ordenha após um único período de 4 horas de separação dos cordeiros apresenta boa precisão na estimativa da produção total de leite.

\section{Literatura Citada}

BENCINI, R.; MARTIN, G.B.; PURVIS, I.W. et al. Use of oxytocin to measure milk output in Merino ewes and its effect on fat content. Australian Journal of Experimental Agriculture, v.32, p.601-603, 1992

BOYLAN, W.J. The genetic basis of milk production in sheep. In: BOYLAN, W.J. (Ed.) North American Dairy Sheep Symposium. St. Paul: University of Minnesota, 1989. p.1-8.

CORBETT, J.L. Variation in the yield and composition of milk of grazing merino ewes. Australian Journal of Agricultural Research, v.19, p.283-294, 1968.

DONEY, J.M.; PEART, J.N.; SMITH, W.F. et al. A consideration of the techniques for estimation of milk yield by suckled sheep and a comparison of estimates obtained by two methods in relation to the effect of breed, level of production and stage of lactation. Journal of Agriculture Science, v.92, p.123$132,1979$.

GEENTY, K.G. Lactation performance, growth, and carcass composition of sheep. I. Milk production, milk composition, and live weights of Romney, Corriedale, Dorset, Romney X Dorset, and Dorset X Romney ewes in relation to the growth of their lambs. New Zealand Journal of Agricultural Research, v.22, p.241-250, 1979

GODFREY, R.W.; GRAY, M.L.; COLLINS, J.R. Lamb growth and milk production of hair and wool sheep in a semi-arid tropical environment. Small Ruminant Research, v.24, p.77-83, 1997.
HAFEZ, E.S.E. Reprodução animal. 6.ed. São Paulo: Manole, 1995. 582p.

INSTITUTO ADOLFO LUTZ. Normas Analíticas do Instituto Adolfo Lutz. Métodos Químicos e Físicos para Análise de Alimentos. 3.ed. São Paulo: Instituto Adolfo Lutz, 1985.

LEMOS NETO, M.J.; CUNHA, E.A. Comparação de métodos estimativos da produção de leite de ovelhas à pasto. Boletim de Indústria Animal, v.51, n.2, p.139-142, 1994.

LENTNER, M.; BISHOP, T. Experimental design and analysis. Blacksburg: Valley Book Company, 1986. 565p.

MARNET, P.G.; McKUSICK, B.C. Regulation of milk ejection and milkability in small ruminants. Livestock Production Science, v.70, p.125-133, 2001.

MINOLA, J.; GOYENECHEA, J. Praderas \& Lanares: Producción ovina en alto nivel. Montevideo: Editorial Hemisfério Sur, 1975. 365p

RAMSEY, W.S.; HATFIELD, P.G.; WALLACE, J.D. et al. Relationships among ewe milk production and ewe and lamb forage intake in Targhee ewes nursing single or twin lambs. Journal of Animal Science, v.72, n.4, p.811-816, 1994.

RAMSEY, W.S.; HATFIELD, P.G.; WALLACE, J.D. Relationships among ewe milk production and ewe and lamb forage intake in Suffolk and Targhee ewes nursing single or twin lambs. Journal of Animal Science, v.76, n.5, p.12471253, 1998.

STATISTICAL ANALYSES SYSTEM - SAS. SAS/STAT User's guide. version 6, v.1, 4.ed. Cary: 1994. 943p.

SNOWDER, G.D.; GLIMP, H.A. Influence of breed, number of suckling lambs, and stage of lactation on ewe milk production and lamb growth under range conditions. Journal of Animal Science, v.69, p.923-930, 1991.

WOHLT, J.E.; FOY, W.L.; KNIFFEN, D.M. et al. Milk yield by Dorset ewes as affected by sibling status, sex and age of lamb, and measurement. Journal of Dairy Science, v.67, p.802-807, 1984.

ZAMIRI, M.J; QOTBI, A.; IZADIFARD, J. Effect of daily oxytocin injection on milk yield and lactation length in sheep. Small Ruminant Research, v.40, n.2, p.179-185, 2001.

Recebido em: 02/09/03 Aceito em: 05/04/04 